\title{
Selective cancer cell killing by $\alpha$-tocopheryl succinate
}

\author{
J Neuzil, T Weber, N Gellert and C Weber \\ Institute for Prevention of Cardiovascular Diseases, Ludwig Maximilians University, Pettenkoferstrasse 9, 80336 Munich, Germany
}

\begin{abstract}
Summary We report that $\alpha$-tocopheryl succinate, a vitamin $E$ analogue with pro-apoptotic properties, selectively kills cells with a malignant or transformed phenotype, i.e. multiple haematopoietic and carcinoma cell lines, while being non-toxic to normal, i.e. primary and nontransformed cells. These findings strongly suggest a potential of this micronutrient in the therapy and/or prevention of cancer without significant side-effects. (C) 2001 Cancer Research Campaign http://www.bjcancer.com
\end{abstract}

Keywords: vitamin E analogue; malignant cells; apoptosis; selectivity

Cancer is one of the most common causes of mortality, hence the search for anticancer drugs has been intense. At present, most substances, whether used in clinical applications or in experimental settings, are relatively non-specific, often exerting adverse effects on normal cells. For instance, the established and widely used chemotherapeutic drug adriamycin (doxorubicin) is associated with cardiomyopathy consisting of congestive heart failure and dysrhythmias, probably due to toxic effects on cardiomyocytes (Henderson and Frei, 1980). Inducers of apoptosis, secreted by cells of the immune system, including the tumour necrosis factor-related apoptosis-inducing ligand, are toxic towards normal cells, such as hepatocytes (Jo et al, 2000).

We have observed recently that $\alpha$-tocopheryl succinate $(\alpha$ TOS), an esterified vitamin $\mathrm{E}$ analogue lacking the antioxidant activity of $\alpha$-tocopherol, induced apoptosis in Jurkat $\mathrm{T}$ lymphoma cells (Neuzil et al, 1999). More recently, we found $\alpha$-TOS to be pro-apoptotic for human colon cancer cells while normal skin fibroblasts were resistant (Neuzil et al, 2001). Together with data by others (Jha et al, 1999) suggesting a selective toxicity of $\alpha$-TOS for malignant cells, these findings prompted us to systematically investigate this potentially important feature. Here we show that $\alpha$-TOS preferentially kills malignant cells while showing very limited or no toxicity towards normal cells.

\section{MATERIALS AND METHODS}

\section{Cell culture}

Suspension cells were maintained in RPMI-1640 supplemented with $10 \%$ FCS plus antibiotics, adherent cells were grown in DMEM plus 10\% FCS and antibiotics, while endothelial cells were cultures in endothelial cell medium with growth factors (Promo Cell) and antibiotics.

Received 6 June 2000

Revised 8 September 2000

Accepted 18 September 2000

Correspondence to: J Neuzil. E-mail: jneuzil@klp.med.uni-muenchen.de or C Weber. E-mail: cweber@klp.med.uni-muenchen.de

\section{Apoptosis induction and assessment}

Apoptosis was induced by addition of $50 \mu \mathrm{M}$ (final concentration) of $\alpha$-TOS dissolved in DMSO, controls were treated with DMSO only. For suspension cells, cell density was $0.5 \times 10^{6}$ per $\mathrm{ml}$ at the onset of treatment, malignant adhesion cells were treated when $70-80 \%$ confluent, while normal adhesion cells were left to grow to confluency before treatment.

Apoptosis was assessed in suspension cells by the annexin V-FITC method as described earlier (Neuzil et al, 1999) and in adherent cells by the TUNEL-FITC method according to the manufacturer's protocol (Boehringer, Germany). The percentage of annexin V-positive cells was determined by flow cytometry (Becton Dickinson) and that of TUNEL-FITC-positive cells by scoring at least 100 cells in a fluorescent microscope.

\section{RESULTS AND DISCUSSION}

We studied the effect $\alpha$-TOS in a wide range of cell lines and normal cells. Strikingly, all cell lines tested were susceptible to $\alpha$-TOS, as treatment with a pharmacological dose of $50 \mu \mathrm{M}$ for $12 \mathrm{~h}$ triggered apoptosis in $28-65 \%$ of the cells (Table 1$)$. In general, leukaemic cell lines, including monocytic and macrophage cell lines, B and T lymphoma cells, were more sensitive towards $\alpha$-TOS than adherent carcinoma cell lines. Notwithstanding, $\alpha$-TOS was pro-apoptotic towards lung, breast and colorectal cancer cells. Moreover, $\alpha$-TOS efficiently killed p53and $\mathrm{p}^{21^{\text {Waf }}{ }^{/ / C i p l} 1}$-deficient mutants of the HCT-116 colon cancer cell line (not shown). Since mutations of tumour suppression genes are frequent complications in cancer chemo- and radiotherapy, this highlights the potential of $\alpha$-TOS as an anticancer agent (Kaelin, 1999).

In contrast, normal cell types, including haematopoietic cells, fibroblasts, endothelial cells, cardiomyocytes, hepatocytes and smooth muscle cells, showed no susceptibility to apoptosis induced by $\alpha$-TOS. This can be exemplified by cardiomyocytes where the effects of pro-apoptotic stimuli on morphology, cytoskeleton and beating rate were compared. While $\alpha$-TOS had no effect, adriamycin induced morphological and cytoskeletal changes and 
Table $1 \alpha$-TOS induces apoptosis in transformed but not normal cells

\begin{tabular}{|c|c|c|}
\hline \multirow[t]{2}{*}{ Cell type } & \multicolumn{2}{|c|}{ Apoptosis $^{a}$} \\
\hline & Control & $\alpha-$ TOS \\
\hline \multicolumn{3}{|l|}{ Haematopoietic cell lines } \\
\hline NSF/N1.H7 & $5.7 \pm 3.2$ & $36.4 \pm 4.8$ \\
\hline HL-60 & $8.1 \pm 2.6$ & $52.2 \pm 7.3$ \\
\hline THP-1 & $5.1 \pm 2.8$ & $48.8 \pm 8.9$ \\
\hline U937 & $8.5 \pm 3.8$ & $59.6 \pm 7.9$ \\
\hline J774 & $8.1 \pm 3.3$ & $65.4 \pm 9.2$ \\
\hline Mono Mac 6 & $6.2 \pm 2.1$ & $54.7 \pm 7.6$ \\
\hline Jurkat & $8.9 \pm 3.1$ & $45.2 \pm 6.8$ \\
\hline K-562 & $4.5 \pm 1.4$ & $37.7 \pm 5.2$ \\
\hline HPB & $6.5 \pm 2.1$ & $35.8 \pm 4.7$ \\
\hline REH & $7.2 \pm 3.8$ & $46.9 \pm 6.5$ \\
\hline CEM & $6.5 \pm 2.1$ & $44.8 \pm 7.8$ \\
\hline Raji & $8.2 \pm 2.1$ & $56.3 \pm 8.5$ \\
\hline Nalm-6 & $6.9 \pm 3.5$ & $49.6 \pm 6.8$ \\
\hline \multicolumn{3}{|l|}{ Adenocarcinoma lung cell line } \\
\hline A549 & $1.1 \pm 0.5$ & $28.1 \pm 4.2$ \\
\hline \multicolumn{3}{|l|}{ Breast carcinoma cell line } \\
\hline MCF-7 & $12.3 \pm 1.5$ & $36.3 \pm 7.3$ \\
\hline \multicolumn{3}{|l|}{ Bronchocarcinoma cell line } \\
\hline BEAS-2B & $1.9 \pm 1.1$ & $36.2 \pm 5.9$ \\
\hline \multicolumn{3}{|l|}{ Colon carcinoma cell lines } \\
\hline CaCo-2 & $6.5 \pm 2.2$ & $63.1 \pm 9.8$ \\
\hline HCT-116 & $7.5 \pm 1.1$ & $37.3 \pm 4.8$ \\
\hline HCT-15 & $3.5 \pm 1.6$ & $32.3 \pm 4.5$ \\
\hline DKO-1 & $6.5 \pm 3.1$ & $45.2 \pm 6.3$ \\
\hline DKO-3 & $6.1 \pm 4.5$ & $43.2 \pm 7.1$ \\
\hline DKS-5 & $5.5 \pm 3.1$ & $41.2 \pm 6.4$ \\
\hline DKS-8 & $7.2 \pm 1.9$ & $37.2 \pm 5.8$ \\
\hline DLD-1 & $5.2 \pm 1.8$ & $32.3 \pm 5.3$ \\
\hline LS1034 & $4.2 \pm 2.6$ & $35.9 \pm 6.9$ \\
\hline \multicolumn{3}{|l|}{ Normal cells } \\
\hline Mouse peritoneal macrophages & $2.1 \pm 1.1$ & $5.5 \pm 3.4$ \\
\hline Human peripheral monocytic cells & $3.5 \pm 2.8$ & $6.2 \pm 4.1$ \\
\hline Human monocyte-derived macrophages & $2.9 \pm 1.5$ & $5.2 \pm 1.5$ \\
\hline Human skin fibroblasts ${ }^{b}$ & $3.5 \pm 0.9$ & $6.1 \pm 2.5$ \\
\hline Human foreskin fibroblasts & $3.8 \pm 3.2$ & $6.5 \pm 4.7$ \\
\hline Human umbilical vein endothelial cells & $3.1 \pm 1.2$ & $6.5 \pm 4.2$ \\
\hline Rat intestinal epithelial cells & $1.8 \pm 1.6$ & $3.5 \pm 4.8$ \\
\hline Rat neonatal cardiomyocytes & $1.1 \pm 0.9$ & $4.2 \pm 3.1$ \\
\hline Rat neonatal hepatocytes & $2.5 \pm 1.9$ & $4.3 \pm 3.2$ \\
\hline Rat smooth muscle cells & $2.5 \pm 1.8$ & $4.9 \pm 3.2$ \\
\hline
\end{tabular}

aApoptosis was assessed following 12-h exposure of the cells to $50 \mu \mathrm{M} \alpha$-TOS. For adherent cells, the extent of apoptosis is expressed as a sum of the corresponding values for cells that remained attached and those that detached during the experiment. Apoptosis extent was assessed by the annexin $V$ method for suspension cells and TUNEL staining for adherent cells, and is expressed in \% apoptotic cells as mean $\pm \mathrm{SD}(n=3-6)$. ${ }^{\mathrm{b}}$ Normal proliferating adherent cells were left to reach confluence before treatment

decreased beating rate (not shown). These findings are complemented by reports which showed no toxic effect of $\alpha$-TOS on normal fibroblasts (Jha et al, 1999) or prostate cells (Israel et al, 2000 ), and by a finding that $\alpha$-TOS was toxic towards malignant but protective for normal stem cells (Fariss et al, 1994).

The reasons for the selectivity of $\alpha$-TOS are not known at present. However, the fact that it appears to affect rapidly proliferating cells is suggestive of a role of the cell cycle in sensitivity of malignant cells to the vitamin $\mathrm{E}$ analogue. We have found that pro-apoptotic activity of $\alpha$-TOS positively correlated with its inhibitory activity on protein kinase C (PKC) (Neuzil et al, 2001), and PKC activity has been associated with a more proliferative and invasive phenotype of malignant cells, as shown e.g. for breast (Ways et al, 1995) or renal carcinoma cells (Engers et al, 2000). Moreover, PKC is also involved in fast transition through the cell cycle by regulating the cell cycle checkpoint proteins $\mathrm{p}^{21^{1 f^{1} / / C i p l}}$ and $\mathrm{p} 27^{\mathrm{Kipl}}$ (Frey et al, 1997), and $\alpha$-TOS has been shown to decrease levels of the cdk2-cyclin A complex and increased $\mathrm{p}^{21^{\text {Waf }}{ }^{1 / C^{\prime} p^{1}}}$ in a human breast cancer cell line (Turley et al, 1997). Similarly, treatment of colon cancer cells with Trolox, a watersoluble analogue of vitamin E, led to the expression of $\mathrm{p}^{21^{1 \text { Waf }}{ }^{1 / C i p} 1}$ and sensitization of the cells towards 5-fluorouracil (Chinery et al, 1997). Notably, we have found that normal adherent cells which were confluent and thus contact-arrested and quiescent were resistant to $\alpha$ TOS-induced toxicity (not shown). 
In conclusion, our results strongly suggest that $\alpha$-TOS, a pharmacologically relevant micronutrient without known side-effects (Bendich and Machlin, 1988), is a potent pro-apoptotic agent for a variety of malignant cells, while being non-toxic for normal cells, and warrants testing as an anticancer drug or adjuvant in experimental animal models of tumorigenesis and leukaemia. This notion is further encouraged by recent findings that $\alpha$-TOS inhibited tumour growth in nude mice with colon-cancer xenografts, similarly or more potently than did other experimental or established anticancer agents (Neuzil et al, 2001; Chinery et al, 1997). Furthermore, free vitamin E or $\alpha$-tocopheryl acetate, the usual pharmacological form of vitamin E, do not have pro-apoptotic activity (Quian et al, 1997; Neuzil et al, 1999). Hence, our results may have important implications for therapy and prevention of cancer.

\section{REFERENCES}

Bendich A and Machlin LJ (1988) Safety of oral intake of vitamin E. Am J Clin Nutr 48: $612-619$

Chinery R, Brockman JA, Peeler Mo, Shyr Y, Beauchamp RD and Coffey RJ (1997) Antioxidants enhance the toxicity of chemotherapeutic agents in colorectal cancer: A p53-independent induction of $\mathrm{p} 21^{\text {Waf//Cipl }}$ via C/EBP $\beta$. Nature Med 3 : $1233-1241$

Engers R, Mrzyk S, Springer E, Fabbro D, Weissgerber G, Gernharz CD and Gabbert HE (2000) Protein kinase $C$ in human renal cell carcinomas: role in invasion and differential isoenzyme expression. Br J Cancer 82: 1063-1069

Fariss MW, Fortuna MB, Everett CK, Smith JD, Trent DF and Djuric Z (1994) The selective antiproliferative effects of $\alpha$-tocopheryl hemisuccinate and cholesteryl hemisuccinate on murine leukemia cells result from the action of the intact compounds. Cancer Res 54: 3346-3351

Frey MR, Saxon ML, Zho X, Rollins A, Evans SS and Black JD (1997) Protein kinase $\mathrm{C}$ isozyme-mediated cell cycle arrest involves induction of $\mathrm{p} 21^{\text {Wafl/Cipl }}$ and $\mathrm{p} 27^{\text {Kipl }}$ and hypophosphorylation of the retinoblastoma protein in intestinal epithelial cells. $J$ Biol Chem 272: 9424-9435

Henderson IC and Frei E (1980) Adriamycin cardiotoxicity. Am Heart J 99: 671-674

Israel K, Yu W, Sanders BG and Kline K (2000) Vitamin E succinate induces apoptosis in human prostate cancer cells: role for Fas in vitamin E succinatetriggered apoptosis. Nutr Cancer 36: 90-100

Jha MN, Bedford JS, Cole WC, Edward-Prasad J and Prasad KN (1999) Vitamin E (d- $\alpha$-tocopheryl succinate) decreases mitotic accumulation in gamma-irradiated human tumor, but not in normal cells. Nutr Cancer 35: 189-194

Jo M, Kim TH, Seol DW, Esplen JE, Dorko K, Billiar TR and Strom SC (2000) Apoptosis induced in normal human hepatocytes by tumor necrosis factor-related apoptosis-inducing ligand. Nature Med 6: 564-567

Kaelin WG (1999) Choosing anticancer drug targets in the postgenomic era. J Clin Invest 104: 1645-1506

Neuzil J, Svensson I, Weber T, Weber C and Brunk U (1999) $\alpha$-Tocopheryl succinate-induced apoptosis in Jurkat T cells involves caspase-3 activation, and both lysosomal and mitochondrial destabilisation. FEBS Lett 445 : 295-300

Neuzil J, Weber T, Schroeder A, Lu M, Ostermann G, Gellert N, Mayne GC, Olejnicka B, Negre-Salvayre A, Sticha M, Coffey RJ and Weber C (2001) Induction of cancer cell apoptosis by $\alpha$-tocopheryl succinate: molecular pathways and structural requirements. FASEB J: in press

Qian M, Kralova J, Yu W, Bose HR, Dvorak M, Sanders BG and Kline K (1997) c-Jun involvement in vitamin E succinate induced apoptosis of reticuloendotheliosis virus transformed avian lymphoid cells. Oncogene $\mathbf{1 5}$ 223-230

Turley JM, Ruscetti FW, Kim SJ, Fu T, Gou FV and Birchenall-Roberts MC (1997) Vitamin E succinate inhibits proliferation of BT-20 human breast cancer cells: increased binding of cyclin A negatively regulates E2F transactivation activity. Cancer Res 57: 2668-2675

Ways DK, Kukoly CA, deVente J, Hooker JL, Bryant WO, Posekany KJ, Fletscher DJ, Cook PP and Parker PJ (1995) MCF-7 breast cancer cells transfected with protein kinase $\mathrm{C}-\alpha$ exhibit altered expression of other protein kinase $\mathrm{C}$ isoforms and display a more aggressive neoplastic phenotype. J Clin Invest $\mathbf{9 5}$ : 1906-1915 